\title{
Solid state N M R, IR and X-ray diffraction studies of the structure and motion of L-leucinamide
}

\author{
Y ulan W ang, ${ }^{a}$ Peter S. B elton, ${ }^{*}, \mathrm{a}$ H uiru Tang, ${ }^{\text {a }}$ Nikolaus W ellner, ${ }^{\mathrm{a}}$ \\ Sian C. D avies ${ }^{b}$ and D avid L. H ughes ${ }^{b}$ \\ a Institute of Food R esearch, N orwich L aboratory, N orwich R esearch Park, C olney, N orwich, \\ UK NR 4 7UA \\ ${ }^{b} \mathrm{~N}$ itrogen Fixation L aboratory, J ohn I nnes Centre, N orwich R esearch Park, Colney, N orwich, \\ UK NR 4 7UH
}

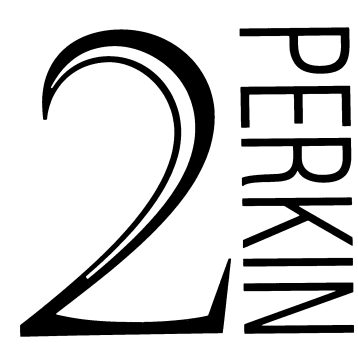

Crystalline L-leucinamide has been studied by ${ }^{13}$ C C P/M A S N M R, F TIR spectroscopy and X-ray crystallography. The ${ }^{13} \mathrm{C} \mathrm{C} \mathrm{P/M} \mathrm{A} \mathrm{S} \mathrm{spectrum} \mathrm{of} \mathrm{crystalline} \mathrm{L-leucinamide} \mathrm{has} \mathrm{been} \mathrm{assigned} \mathrm{using} \mathrm{the}$ depolarisation-repolarisation method. Two magnetically non-equivalent molecules in the unit cell have been found from the ${ }^{13} \mathrm{C} \mathrm{CP/M} \mathrm{A} \mathrm{S} \mathrm{spectra.} \mathrm{N} \mathrm{on-equivalence} \mathrm{is} \mathrm{also} \mathrm{observed} \mathrm{in} \mathrm{the} \mathrm{F} \mathrm{TIR} \mathrm{spectrum.} \mathrm{The}$ molecular dynamics were studied by measuring ${ }^{13} \mathrm{C}$ spin-lattice relaxation in both laboratory and rotating frames. R esults show that the mobilities of the two molecules are very different. Spin-lattice relaxation times for the two $\alpha$ carbons differ by an order of magnitude. D etermination of the crystal structure by $X$ ray crystallography confirmed the existence of two distinct molecules in the unit cell; these differed in the orientation of the amide groups and in their involvement in the hydrogen bonding scheme, which may account for the observed $\mathbf{N}$ M R behaviour.

\section{Introduction}

$\mathrm{L}-\mathrm{L}$ eucinamide readily forms eutectic mixture with $\mathrm{N}$-benzyloxycarbonyl-L-tyrosine ethyl ester (N-Z-TyrOEt), in which a<smiles>CC(C)CC(N)C(N)=O</smiles>

transesterification reaction can take place with enzymatic catalysis. $^{1-3} \mathrm{H}$ owever, little is known about the mechanisms of reaction at the molecular level and the major structural factors governing the ability of these molecules to form eutectic mixtures. We therefore began a systematic study of the properties of these amino acid derivatives and their mixtures.

The ${ }^{1} \mathrm{H}$ NMR relaxation behaviour of L-leucinamide showed $^{4}$ that the reorientations of the methyl and amino groups were the major relaxation mechanisms for the spinlattice relaxation. It was also observed that there were two different $\mathrm{G}$ aussian components in the transverse relaxation process, which could be assigned to the aliphatic and amino groups. To investigate further the solid state structure and motion, we now report on solid state ${ }^{13} \mathrm{C} C P / M A S N M R, I R$ spectroscopic and $X$-ray crystallographic results for the crystalline form of L-leucinamide.

\section{Experimental}

\section{Sample preparation}

The free base of L-leucinamide was prepared from the corresponding hydrochloride salt (Sigma) by neutralising its methanolic solution with potassium hydroxide dissolved in methanol, followed by filtration and rotary evaporation to remove methanol. L-L eucinamide was then recrystallised from benzene several times. I ts purity was confirmed with high resolution ${ }^{1} \mathrm{H} N \mathrm{~N} R$ at $400 \mathrm{M} \mathrm{H}$ z on a J EOL GX -400 spectrometer. A deuterium exchanged sample was prepared by stirring the
L-leucinamide in deuteriated water for ca. $2 \mathrm{~h}$, followed by freeze-drying; this process was repeated three times to ensure the completion of exchange.

\section{Solid state N M R spectroscopy}

A II CP/M A S N M R experiments were carried out on a Bruker M SL-300 spectrometer operating at a ${ }^{1} \mathrm{H}$ frequency of 300.13 $\mathrm{M} \mathrm{Hz}$ and ${ }^{13} \mathrm{C}$ frequency of $75.46 \mathrm{M} \mathrm{Hz}$. CP/M A S spectra were recorded using a standard Bruker double-bearing magic-angle sample-spinning probe. A pproximately $200 \mathrm{mg}$ of sample were packed into a $7 \mathrm{~mm}$ zirconia rotor with a $\mathrm{K} \mathrm{el-F}$ cap and spun at 3-4 kHz. A single contact spin-lock cross-polarisation sequence ${ }^{5}$ was used with a pulse to flip back the remaining ${ }^{1} \mathrm{H}$ magnetisation after acquisition. ${ }^{6}$ The ${ }^{1} \mathrm{H} 90^{\circ}$ pulse length was $4.3 \mu \mathrm{s}$. F reeinduction decays were measured with $2 \mathrm{~K}$ data points and zero filled to $8 \mathrm{~K}$ before $\mathrm{F}$ ourier transformation. Between 320 and 600 transients were accumulated for each spectrum with a contact time of $1 \mathrm{~ms}$ and repetition time of $4 \mathrm{~s}$. The chemical shift was referenced externally to the higher frequency resonance of solid adamantane at $38.56 \mathrm{ppm} .{ }^{7}$ The magic angle was accurately set using $\mathrm{KBr}^{8}$ Spectral deconvolution was carried out using F ELIX -2.3 (Biosym Technologies) operating on a Silicon Graphics computer. Lineshapes were fitted to a Lorentzian function. Cross-polarisation-depolarisation (CPDP) and cross-polarisation-depolarisation-repolarisation (CPDPRP) experiments were conducted as described elsewhere. $^{9}$

Spin-lattice relaxation times of carbon $\left(\mathrm{T}_{1^{-}}{ }^{13} \mathrm{C}\right)$ were measured using the TICP method described by Torchia ${ }^{10}$ (CP-90 $\tau-90^{\circ}$-A cquire). Fourteen experiments were carried out with delay time $(\tau)$ varying from $10 \mathrm{~ms}$ to $5 \mathrm{~s}$. 256 Transients were

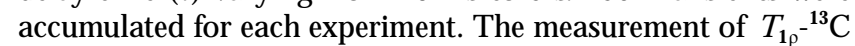
was carried as follows: a carbon magnetisation was first established by a CP procedure; the contact between protons and carbons was then broken by simply turning off the proton $\mathrm{R} \mathrm{F}$; ${ }^{13} \mathrm{C}$ magnetisation was sampled with dipolar decoupling of the protons after holding the carbon spins in their radio frequency spin-locking rotating field ( $58 \mathrm{kHz}$ ) for between $10 \mu \mathrm{s}$ and 200 $\mathrm{ms}^{11}$ Carbon and proton cross polarisation time $\mathrm{T}_{\mathrm{CH}}$ was 
Table $1{ }^{13} \mathrm{C}$ CP/M A S N M R data for L-leucinamide and the deuteriated sample in the solid state

\begin{tabular}{|c|c|c|c|c|c|}
\hline Type of carbon & $\delta$ in solid & L inewidth $-\mathrm{H}(\mathrm{D})^{\mathrm{a}} / \mathrm{H} \mathrm{z}$ & $\mathrm{T}_{1^{-}}{ }^{13} \mathrm{C}-\mathrm{H}(\mathrm{D}) / \mathrm{s}$ & $\mathrm{T}_{1 \mathrm{p}}{ }^{13} \mathrm{C}-\mathrm{H}(\mathrm{D}) / \mathrm{ms}$ & $\mathrm{T}_{\mathrm{CH}}-\mathrm{H}(\mathrm{D}) / \mu \mathrm{S}$ \\
\hline$C=0$ & $\begin{array}{l}182.3 \\
181.4\end{array}$ & $\begin{array}{l}438(351) \\
151(231)\end{array}$ & $\begin{array}{l}33.0(37.2) \\
-\mathrm{b}\end{array}$ & $\begin{array}{l}47.9(80.3) \\
-\mathrm{b}\end{array}$ & $\underset{-b}{230}(109)$ \\
\hline \multirow[t]{2}{*}{$\mathrm{C}_{\alpha}$} & 58.1 & $291(279)$ & $2.3(2.2)$ & $12.4(87.6)$ & $44(140)$ \\
\hline & 53.7 & $321(303)$ & $23.6(20.9)$ & 38.9 (178.8) & 45 (110) \\
\hline \multirow{2}{*}{$\mathrm{C}_{\beta}$} & 45.8 & $174(231)$ & $0.6(0.6)$ & $51.3(152.1)$ & 38 (65) \\
\hline & 41.9 & 258 (315) & $3.2(3.4)$ & $54.9(246)$ & $32(67)$ \\
\hline \multirow{2}{*}{$\mathrm{C}_{\gamma}$} & 26.9 & 102 (108) & $1.2(1.1)$ & 67.9 (264) & 85 (170) \\
\hline & 25.8 & 96 (99) & $-{ }^{b}$ & $-{ }^{b}$ & \\
\hline \multirow[t]{2}{*}{$\mathrm{C}_{\delta 1}$} & 25.6 & $78(60)$ & $0.6(0.7)$ & $82.8(194.2)$ & $130(290)$ \\
\hline & 25.1 & $90(90)$ & $0.5(0.5)$ & $32.9(145.7)$ & $230(280)$ \\
\hline \multirow[t]{2}{*}{$\mathrm{C}_{\delta 2}$} & 23.7 & $120(84)$ & $0.7(0.8)$ & $69.1(212.1)$ & $230(240)$ \\
\hline & 23.3 & $90(81)$ & $0.6(0.6)$ & $83.0(135.1)$ & $290(400)$ \\
\hline
\end{tabular}

a The first value in each column is for the non-deuteriated sample. The figure in brackets is for the deuteriated sample. ${ }^{\text {b }}$ Peaks are overlapped, the data cannot be derived.

measured by acquiring a series of spectra with variable contact time between $20 \mu \mathrm{s}$ and $15 \mathrm{~ms}^{12} 256$ Transients were accumulated for each experiment.

\section{Infrared spectroscopy}

Fourier-transform IR spectra were recorded on a Bio-R ad FTS-60 spectrometer equipped with a $\mathrm{H} \mathrm{gCdTe}$ detector. Solid samples were ground with $\mathrm{K} \mathrm{Br}$ and pressed into disks. 256 Scans at $2 \mathrm{~cm}^{-1}$ resolution were coadded and the absorption spectrum was calculated with a blank $\mathrm{K} \mathrm{Br}$ disk background.

Solution spectra of L-leucinamide in chloroform were measured with a M icroCircle ATR cell containing a ZnSe crystal (SpectraTech). $256 \mathrm{Scans}$ at $2 \mathrm{~cm}^{-1}$ resolution were coadded and referenced against the empty cell. The spectrum of the solute was obained by digital subtraction of the pure chloroform spectrum, recorded under identical conditions. ATR correction was performed with the BIO-RAD WIN -IR Spectrometer software.

\section{C rystal structure analysis of $\mathrm{L}$-leucinamide}

C rystal data. $\mathrm{C}_{6} \mathrm{H}_{14} \mathrm{~N}_{2} \mathrm{O}, \mathrm{M}=130.2$. $\mathrm{M}$ onoclinic, space group I 2 (equiv. to $\mathrm{N} 0.5$ ) $, a=9.665(1), b=5.9003(6), c=28.716(4)$ $\AA, \beta=92.744(10)^{\circ}, V=1635.7(3) \AA^{3}, Z=8, D_{c}=1.059 \mathrm{~g} \mathrm{~cm}^{-3}$, $\mathrm{F}(000)=576, \mu(\mathrm{M} \mathrm{o}-\mathrm{K} \alpha)=0.07 \mathrm{~mm}^{-1}, \lambda(\mathrm{M} \mathrm{o-K} \alpha)=0.71069 \AA$.

Crystals are clear, colourless plates, often very thin. One, ca. $0.70 \times 0.25 \times 0.15 \mathrm{~mm}$, was mounted in a glass capillary and, after preliminary photographic examination, transferred to an Enraf-N onius CAD 4 diffractometer (with monochromated radiation) for determination of accurate cell parameters (from the settings of 25 reflections, $\theta=8-9^{\circ}$, each centred in four orientations) and for measurement of diffraction intensities (to $\theta_{\max }=25^{\circ}$ ). Of the 1576 independent reflections, 1072 were 'observed' with I $>2 \sigma_{1}$.

During processing, corrections were applied for Lorentzpolarisation effects, slight deterioration (ca. 7.7\% overall), absorption (by semi-empirical $\psi$-scan methods) and to eliminate negative net intensities (by Bayesian statistical methods). The structure was determined by direct methods in the SHELXS program ${ }^{13}$ and refined by full-matrix least-squares methods in SHELXL-93. ${ }^{14} \mathrm{H}$ ydrogen atoms on the carbon atoms were included in idealised positions, but those on the nitrogen atoms were taken from difference maps and included in the refinement with geometrical constraints; the isotropic thermal parameters of most of the $\mathrm{H}$ atoms were allowed to refine freely, except for those in some methyl groups where the $U_{\text {iso }}$ values were set to $1.5 \times U_{\text {eq }}$ of the parent $C$ atoms. Thenonhydrogen atoms were refined with anisotropic thermal parameters. At the conclusion of the refinement, $R=0.087$ and $W R_{2}=0.195^{14}$ for all 1576 reflections weighted $W=\left\{\sigma\left(F_{0}{ }^{2}\right)^{2}+\right.$ $\left.(0.125 P)^{2}\right\}^{-1}$ where $P=\left(F_{o}{ }^{2}+2 F_{c}{ }^{2}\right) / 3$. In the final difference map, the highest peaks (to ca. 0.37 e $\AA^{-3}$ ) were close to the methyl groups.

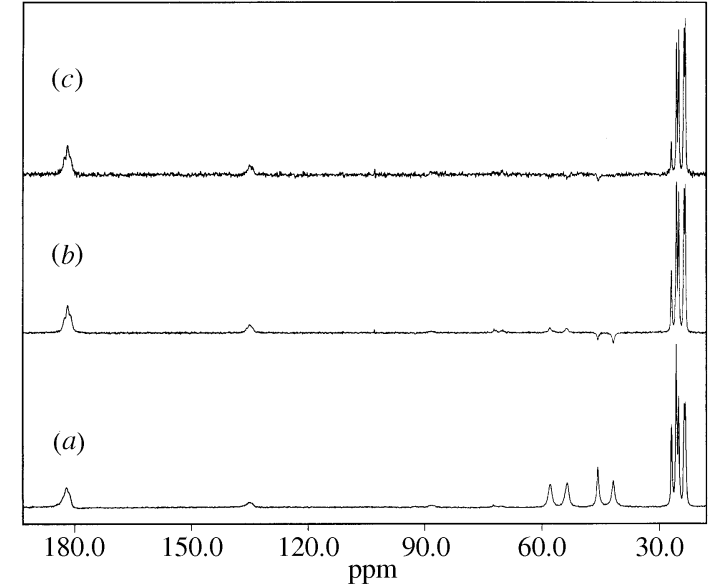

Fig. 1 Solid state ${ }^{13} \mathrm{C}$ N M R spectra of L-leucinamide under the following conditions: (a) cross-polarisation; (b) CP followed by $30 \mu$ s depolarisation time; (c) CP followed by $50 \mu$ s depolarisation time and $15 \mu \mathrm{s}$ repolarisation time

It was not possible to determine the absolute configuration from the X -ray data, but the structure has been refined with the correct stereochemistry knowing that our sample was prepared from L-leucinamide hydrochloride.

Scattering factors for neutral atoms were taken from ref. 15. Computer programs used in this analysis have been noted above or in Table 4 of ref. 16 and were run on a DEC-A IphaStation $2004 / 100$ in the N itrogen Fixation Laboratory, John Innes Centre. Atomic coordinates, thermal parameters and bond lengths and angles have been deposited at the Cambridge Crystallographic D ata Centre (CCDC). $\dagger$

\section{Results and discussion}

\section{Solid state N M R spectroscopy}

Resonance assignment. $A{ }^{13} \mathrm{C} C P / M A S N M R$ spectrum of L-leucinamide is shown in $\mathrm{Fig.} \mathrm{1(a).} \mathrm{The} \mathrm{assignments} \mathrm{are}$ given in Table 1. M ethylene and methine carbons have been assigned by the use of cross-depolarisation (CPDP) and crossrepolarisation (CPDPR P) method. ${ }^{17}$ The CPD $P$ is the reversal of the direction of growth of ${ }^{13} \mathrm{C}$ polarisation when the phase of carbon RF is shifted $180^{\circ}$ after the first cross-polarisation contact. CPDPR P is a second reversal of the growth direction following another $180^{\circ}$ phase change of the carbon $\mathrm{RF}$ after the CPD P step. The polarisation rate of ${ }^{13} \mathrm{C}$ nuclei depends on the magnitude of the dipole-dipole interaction between ${ }^{13} \mathrm{C}$ and

t For details of the CCDC deposition scheme, see 'Instructions for Authors', J. Chem. Soc., Perkin Trans. 2, 1997, Issue 1. A ny request to the C CD C for this material should quote the full literature citation and the reference number 188/64. 


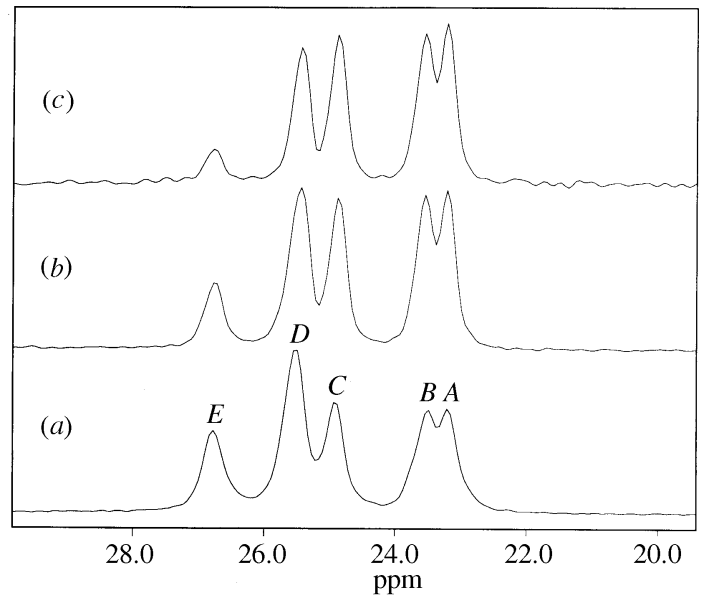

Fig. 2 Expansion of the high field region of the solid state NMR spectra of Fig. 2

${ }^{1} \mathrm{H}$ spins. ${ }^{18}$ Polarisation of methylene carbon is therefore faster than methine carbon. H owever, for methyl carbons the reduction of the local dipole-dipole interactions caused by the rapid methyl group rotation slows polarisation rates to less than those for methylene or methine groups. In CPD PR P experiments it is thus possible to selectively invert methylene signals by judicious choice of depolarisation time. In Fig. 1(b) the reduced signals are therefore assigned to $\mathrm{C}_{\alpha}(-\mathrm{CH})$ and the inverted signals to $\mathrm{C}_{\beta}\left(-\mathrm{CH}_{2}\right)$ when $30 \mu \mathrm{s}$ cross-depolarisation timewas used. This is consistent with the fact that $\mathrm{C}_{\alpha}$ bonded to $\mathrm{N} \mathrm{H}_{2}$ resonates at higher chemical shift than $\mathrm{C}_{\beta}$. Two signals are observed even though the molecular formula predicts only one. It is also possible to eliminate both methylene and methine carbon signals by choosing suitable cross-depolarisation and cross-repolarisation times. Fig. 1(c) shows that both signals were suppressed by choosing $50 \mu \mathrm{s}$ of cross-depolarisation time and $15 \mu \mathrm{s}$ of cross-repolarisation time. $U$ sing this strategy the remaining methine carbon can be assigned.

The region of the spectrum around $25 \mathrm{ppm}$ is shown expanded in Fig. 2(a). Peaks A and B are of equal intensity and assigned to a methyl carbon. $C$ and $D$ are of unequal intensity and $D$ is about twice the intensity of $A, B$ and $C$. It is therefore probably a composite peak. U se of the CPDPR P experiment under conditions that null the methine carbon intensity reduces the intensities of peaks $E$ and $D$ [Fig. 2(c)]. E is therefore assigned to $\mathrm{C}_{\gamma}$ and part of $\mathrm{D}$ also arises from a second $\mathrm{C}_{\gamma}$ resonance. The remaining parts of $D$ and $C$ are assigned to the other methyl carbon. The fact that four methyl carbon peaks are observed is consistent with magnetic inequivalence of two molecules within the system but it is not possible to assign $C_{\delta}$ peaks arising from the same molecule separately from those arising from different molecules. For convenience the peaks at ca. $25 \mathrm{ppm}$ are labelled $\mathrm{C}_{\delta 1}$ and those at ca. $23 \mathrm{ppm} \mathrm{C}_{\delta 2}$. L ine shape analysis of peak $D$ permits the discrimination of the two resonances in this peak and calculation of the linewidths. The peak at $182 \mathrm{ppm}$ is assigned to carbonyl carbon and the one at ca. $135 \mathrm{ppm}$ is a spinning sideband (spinning rate ca. $3.5 \mathrm{kHz}$ ) of the carbonyl carbon. $\mathrm{D}$ ata are given in Table 1.

Inspection of the resonance arising from the $C_{\alpha}$ and $C_{\beta}$ carbons shows that those assigned to $\mathrm{C}_{\alpha}$ are wider than those assigned to $C_{\beta}$ and both are wider than the remaining aliphatic resonances. This is probably due to the well known phenomenon of residual dipolar interaction with ${ }^{14} \mathrm{~N}$ due to secondorder quadrupolar effects. In leucine it was argued ${ }^{17}$ that such effects were not important in $7.0 \mathrm{~T}$ magnetic fields and that residual broadening in $C_{\alpha}$ and $C_{\beta}$ resonances arose from chemical shift dispersions due to magnetic inequivalence effects. In leucinamide two inequivalent $\alpha$ and $\beta$ carbon atoms are clearly observed. E ach resonance is symmetric and can be readily fitted to a single L orentzian line shape (see Table 1). It seems

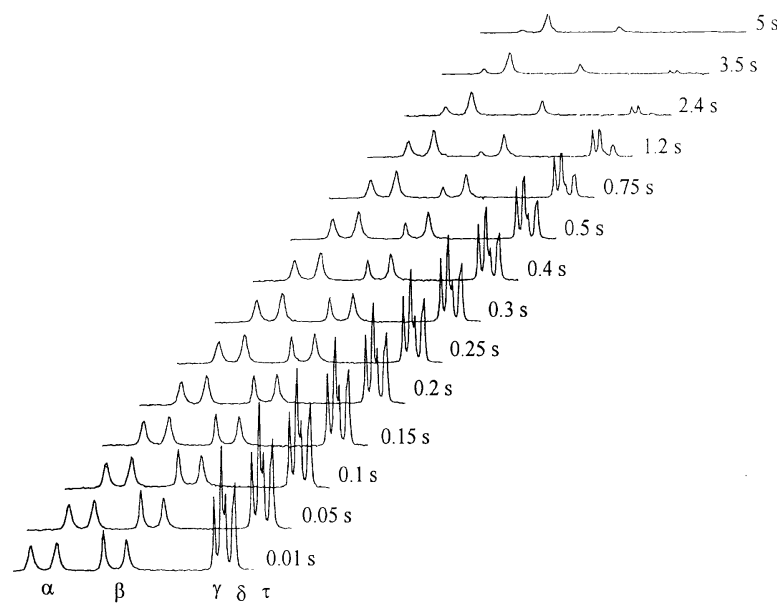

Fig. 3 Stack plot of Fourier transformed ${ }^{13} \mathrm{C}$ spectra with different delay times in the $T_{1}$ measurements

likely therefore that the origin of the linewidth is residual dipolar interactions. The $\mathrm{C}_{\alpha}$ carbon signals are broader than those of the $C_{\beta}$. This is consistent with the fact that the distance between $C_{\alpha}$ and nitrogen is shorter than the $C_{\beta}$ (see Table 2). It is also possible that the line broadening of $C_{\beta}$ is caused by incomplete proton decoupling, since a calculation of the local dipolar field suggests that the $58 \mathrm{kHz}$ decoupling field strength is of the same order of the local field at the carbon atom. The linewidths of both $C_{\alpha}$ lines are similar, but the $C_{\beta}$ line at 45.8 $\mathrm{ppm}$ is significantly narrower than that at $41.9 \mathrm{ppm}$. The differences in width must arise from differences in residual dipolar interactions as a result of the differences in motion. This possibility will be further explored when the relaxation data are considered.

Relaxation time measurements. Fig. 3 shows the stack plot of Fourier transformed spectra obtained with different delay times in the $T_{1}$ measurements. Clearly one of the $\alpha$-carbon atoms relaxes much more slowly $\left(T_{1}=23.6 \mathrm{~s}\right)$ than the other $\left(T_{1}=2.3\right.$ s). Similar observations were made for $\beta$-carbons $\left(T_{1}=3.2,0.55\right.$ s). The differences in $T_{1}$ between the two molecules may be assumed to be due to differences in motion. For one of the molecules, the shortness of the $\alpha 1$ carbon $T_{1}$ implies a fairly rapid motion; similarly both $\beta 1$ and $\beta 2 T_{1}$ values are short, implying fairly rapid motion. The $T_{1}$ values of the $\delta$ carbons are expected to be short due to methyl group rotation; however, the results for the other carbons imply a high degree of skeletal mobility. The $T_{10}$ results do not, in general, reflect the $T_{1}$ results; the large differences observed in the $T_{1}$ data are not apparent in $T_{10}$. This is likely to be due to differences in mechanism of $T_{1}$ and $T_{1 \rho}$ relaxation for carbon. $U$ nder the experimental circumstances that apply here, the spin-locking field is not very much greater than the local dipolar fields. A s a result of this there may be contributions from transverse relaxation effects as well as spin-lattice effects. ${ }^{19}$ For a truly rigid system it would be expected that the size of this effect would depend on the number of attached protons. ${ }^{19}$ This is clearly not the case in the system under study here $\left(T_{1 \rho}-C_{\beta}>T_{1 \rho}-C_{\alpha}\right)$; however, the $T_{1}$ results imply the presence of significant motion and therefore the contribution of the attached protons is attenuated by local motional effects which vary from carbon to carbon. Substitution of deuterium for protons on the amino groups lengthens $\mathrm{T}_{1 \rho}$ and restores the difference between the $\beta$ carbon atoms (Table 1). Such a substitution has been shown to reduce that part of the proton second moment affecting transverse relaxation by a factor of about $2 .{ }^{4} T$ his substitution must also reduce the local static dipolar field experienced by the carbons. U nder these circumstances the ratio of the applied R F field to the local static dipolar field will increase, thus the $T_{1_{0}}-\mathrm{C}$ of deuteriated samples will more accurately reflect spin-lattice processes since it will be much less influenced by spin-spin interactions. The 
Table 2 Bond dimensions in L-leucinamide. Bond lengths are in $\AA$ ngstroms, angles in degrees. E.s.d.s are in parentheses

$\begin{array}{ll}\text { (a) Bond lengths } & \\ \mathrm{C}(11)-\mathrm{O}(111) & 1.238(5) \\ \mathrm{C}(11)-\mathrm{N}(111) & 1.319(6) \\ \mathrm{C}(11)-\mathrm{C}(12) & 1.521(7) \\ \mathrm{C}(12)-\mathrm{N}(121) & 1.468(7) \\ \mathrm{C}(12)-\mathrm{C}(13) & 1.520(7) \\ \mathrm{C}(13)-\mathrm{C}(14) & 1.516(11) \\ \mathrm{C}(14)-\mathrm{C}(15) & 1.346(13) \\ \mathrm{C}(14)-\mathrm{C}(141) & 1.560(14)\end{array}$

(b) Bond angles

$$
\begin{aligned}
& O(111)-C(11)-N(111) \\
& O(111)-C(11)-C(12) \\
& N(111)-C(11)-C(12) \\
& N(121)-C(12)-C(13) \\
& N(121)-C(12)-C(11) \\
& C(13)-C(12)-C(11) \\
& C(14)-C(13)-C(12) \\
& C(15)-C(14)-C(13) \\
& C(15)-C(14)-C(141) \\
& C(13)-C(14)-C(141)
\end{aligned}
$$

$122.6(5)$

$120.9(4)$

$116.3(4)$

$109.2(4)$

$109.9(4)$

$112.3(4)$

$116.2(6)$

120.6(11)

111.9(11)

107.2(10)

(c) Torsion angles

O (111)-C (11)-C(12)-N (121)

$\mathrm{N}(111)-\mathrm{C}(11)-\mathrm{C}(12)-\mathrm{N}(121)$

$O(111)-C(11)-C(12)-C(13)$

$\mathrm{N}(111)-C(11)-C(12)-C(13)$

$N(121)-C(12)-C(13)-C(14)$

$\mathrm{C}(11)-\mathrm{C}(12)-\mathrm{C}(13)-\mathrm{C}(14)$

$C(12)-C(13)-C(14)-C(15)$

$C(12)-C(13)-C(14)-C(141)$

$\mathrm{O}(211)-\mathrm{C}(21)-\mathrm{C}(22)-\mathrm{N}(221)$

$\mathrm{N}(211)-\mathrm{C}(21)-\mathrm{C}(22)-\mathrm{N}(221)$

$O(211)-C(21)-C(22)-C(23)$

$\mathrm{N}(211)-\mathrm{C}(21)-\mathrm{C}(22)-\mathrm{C}(23)$

$N(221)-C(22)-C(23)-C(24)$

$\mathrm{C}(21)-\mathrm{C}(22)-\mathrm{C}(23)-\mathrm{C}(24)$

$C(22)-C(23)-C(24)-C(241)$

$C(22)-C(23)-C(24)-C(25)$

(d) H ydrogen bond dimensions

Bond: D-H $\cdots$ A

$\mathrm{N}(111)-\mathrm{H}(111 \mathrm{a}) \cdots \mathrm{O}\left(211^{\prime \prime}\right)$

$N(111)-H(111 b) \cdots N\left(121^{\prime}\right)$

$\mathrm{N}(211)-\mathrm{H}(211 \mathrm{a}) \cdots \mathrm{N}\left(221^{\prime \prime \prime}\right)$

$\mathrm{N}(211)-\mathrm{H}(211 \mathrm{~b}) \cdots \mathrm{O}$ (111)

$\mathrm{N}(221)-\mathrm{H}(221 \mathrm{a}) \cdots \mathrm{O}(111)$

$\mathrm{N}(121)-\mathrm{H}(121 \mathrm{a}) \cdots \mathrm{N}\left(221^{\mathrm{v}}\right)$

$\mathrm{N}(121)-\mathrm{H}(121 \mathrm{~b}) \cdots \mathrm{O}\left(211^{\mathrm{v}}\right)$

$\mathrm{N}(221)-\mathrm{H}(221 \mathrm{~b}) \cdots \mathrm{O}\left(111^{\mathrm{Iv}}\right)$

$C(21)-O(211)$
$C(21)-N(211)$
$C(21)-C(22)$
$C(22)-N(221)$
$C(22)-C(23)$
$C(23)-C(24)$
$C(24)-C(241)$
$C(24)-C(25)$

$1.245(6)$

$1.334(6)$

$1.512(8)$

$1.465(6)$

$1.532(8)$

$1.467(9)$

$1.512(10)$

$1.55(2)$

$\begin{array}{ll}O(211)-C(21)-N(211) & 120.6(5) \\ O(211)-C(21)-C(22) & 120.9(4) \\ N(211)-C(21)-C(22) & 118.6(4) \\ N(221)-C(22)-C(21) & 113.0(4) \\ N(221)-C(22)-C(23) & 108.1(4) \\ C(21)-C(22)-C(23) & 111.2(5) \\ C(24)-C(23)-C(22) & 118.7(5) \\ C(23)-C(24)-C(241) & 111.6(7) \\ C(23)-C(24)-C(25) & 111.4(8) \\ C(241)-C(24)-C(25) & 109.5(8)\end{array}$

$$
\begin{gathered}
-72.80(64) \\
103.06(49) \\
48.96(64) \\
-135.18(49) \\
-179.10(69) \\
58.72(79) \\
55.37(172) \\
-175.10(121) \\
\\
131.63(48) \\
-50.04(63) \\
-106.65(52) \\
71.69(61) \\
-173.94(61) \\
61.47(75) \\
-174.20(84) \\
63.06(104)
\end{gathered}
$$

Roman superscripts denote symmetry operations:

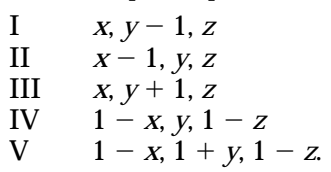

behaviour of $T_{1_{\rho}}$ and $T_{1}$ will therefore become more similar as both are now principally controlled by the modulation of the local magnetic field by molecular and atomic motions. The role of the amino protons in affecting the local static field is reflected in the changes in the cross relaxation rate, $T_{C H}$, on deuteriation. The lengthening of this implies a reduction in the local dipolar field experienced by carbon. The proton $T_{1_{p}}$ data ${ }^{4}$ show a weak minimum ( $\mathrm{N} \mathrm{H}_{2}$ rotation) near room temperature and it might be expected that this would be reflected in an effect on the carbon linewidth on deuteriation ${ }^{20}$ since near $T_{1 \rho}$ minima the coupling of the R F with motion results in poor decoupling effects. In fact, no effect on linewidth is observed (Table 1). This may be attributed to the weakness of the minimum, which in turn reflects only the very small part of the total second moment being modulated by this motion. The static contribution of the protonated amino groups is about $2 \times 10^{8} \mathrm{~s}^{-2}$ where as the second moment modulated by the motion is $0.18 \times 10^{8}$ $\mathrm{s}^{-2} .4$ The distinction between the static and dynamic parts of the second moment also explains why no effect of deuteriation is seen on the carbon $T_{1}$ values. The main component of the dipolar field being modulated by motion arises from attached protons. The more distant amino protons make a negligible contribution.

\section{IR spectroscopy}

Fig. 4(a) shows the spectrum of crystalline L-leucinamide. All 

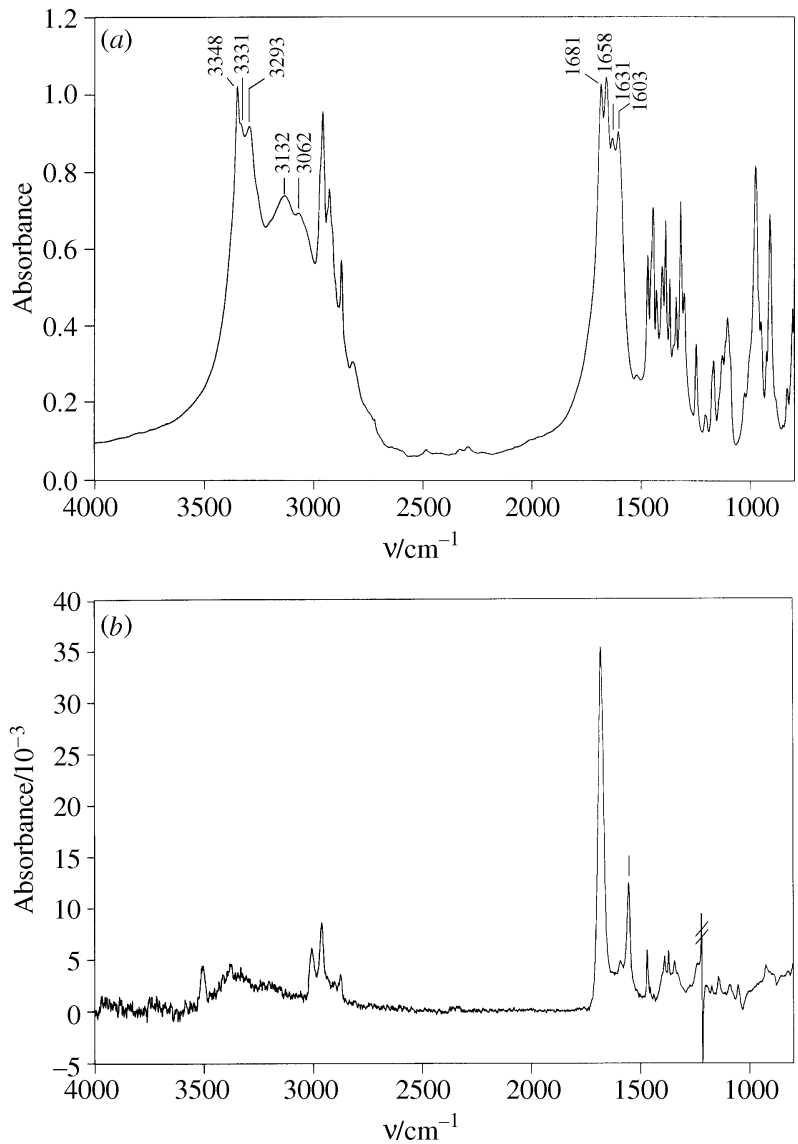

Fig. 4 FTIR spectra of L-leucinamide (a) solid state in $\mathrm{K} \mathrm{Br}$; (b) FTIR ATR spectrum of $\mathrm{L}$-leucinamide in $\mathrm{CHCl}_{3}$ solution, solvent spectrum subtracted. The marked spike in the spectrum is an artifact due to subtraction.

major bands originating from the amide groups were split. The amide I band (predominantly $\mathrm{C}=0$ stretching) at 1681 and 1658 $\mathrm{cm}^{-1}$ and the amidell ( $\mathrm{N} \mathrm{H}_{2}$ scissoring) mode at 1631 and 1603 $\mathrm{cm}^{-1}$ appeared as two doublets of almost equally intense bands. The N H stretching of the amide group was split into a band at $3293 \mathrm{~cm}^{-1}$ and a sharp peak at $3348 \mathrm{~cm}^{-1}$. In the latter case, a shoulder at $3331 \mathrm{~cm}^{-1}$ might suggest the existence of other rotamers. Band splitting was also visible in the broad $\mathrm{NH}$ stretching bands of the amine group at 3062 and $3132 \mathrm{~cm}^{-1}$. However, when the L-leucinamide was dissolved in chloroform, the amide band splitting vanished [Fig. 4(b)] and sharp single bands at 1678 and $1552 \mathrm{~cm}^{-1}$ were observed. In addition the intensities of $\mathrm{NH}$ stretching bands were greatly reduced. This may be due to a reduction in hydrogen bonding in the solvent compared to that in the crystal lattice.

All these vibration modes are strongly affected by the presence of intermolecular hydrogen bonds. The amide I band at $1681 \mathrm{~cm}^{-1}$ (1678 $\mathrm{cm}^{-1}$ in solution) was assigned to relatively free carbonyl groups and the peak at $1658 \mathrm{~cm}^{-1}$ to the hydrogenbonded ones. The two amide II frequencies and the splits in the $\mathrm{NH}$ stretching signalled different hydrogen-bonding environments for the amide $\mathrm{NH}_{2}$ groups and the $\mathrm{NH}$ stretching also indicated two different amine groups.

From intensities of the peaks, it may be inferred that the crystal lattice contained a $1: 1$ ratio of non-equivalent $\mathrm{L}$ leucinamide molecules with clearly distinct hydrogen-bonding patterns.

\section{Crystal structure results}

$\mathrm{X}-\mathrm{R}$ ay analysis shows that there are two distinct, independent molecules, I and II, (Fig. 5) in crystals of L-leucinamide. M olecular dimensions are given in Table 2 . The bond dimensions in the two molecules are similar and as expected. There is (a) $\mathrm{H}(121 \mathrm{a}) \mathrm{H}(121 \mathrm{~b})$
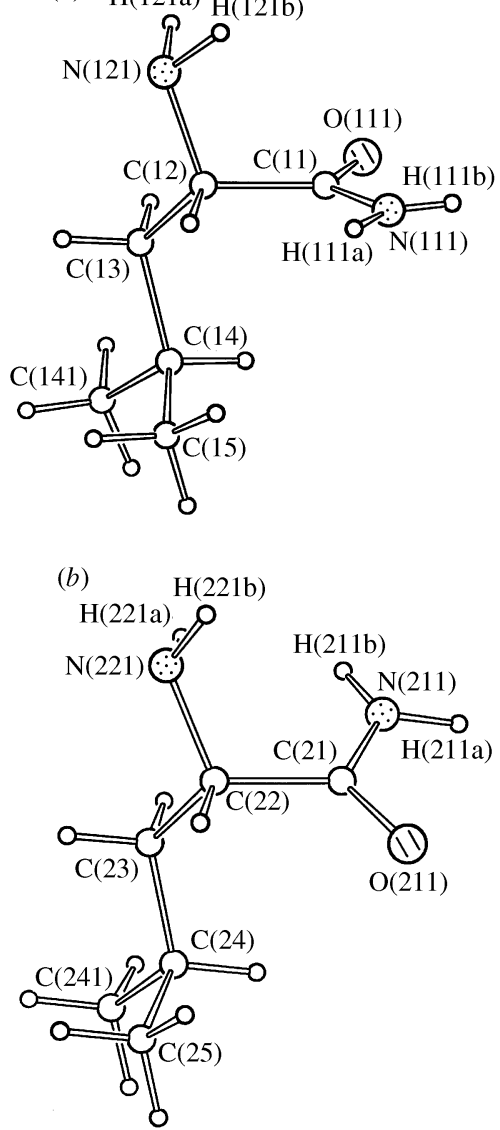

Fig. 5 Corresponding views of the two molecules I (a), and II (b), in the crystal of L-leucinamide, showing the atom numbering scheme

considerable thermal motion in the butyl groups of both molecules and the bond lengths in this region are not precisely determined. The principal difference between I and II is in the orientation of the amide group - there is rotation about the $\mathrm{C}$ (amide) $-\mathrm{C}_{\alpha}$ bond so that the $\mathrm{N}$ (amide) $-\mathrm{C}-\mathrm{C}-\mathrm{C}$ torsion angles are $-135.2(5)$ and $71.7(6)^{\circ}$ and the $\mathrm{O}-\mathrm{C}-\mathrm{C}-\mathrm{C}$ angles $49.0(6)$ and $-106.7(5)^{\circ}$ in molecules I and II respectively. There are differences, too, in the orientation of the amine groups of $N(121)$ and $N(221)$. Both these differences are related to the hydrogen bonding in the crystal.

$\mathrm{H}$ ydrogen bonding links the molecules in bilayer parallel to the ab plane. Within each monolayer, there are five short $\mathrm{H} \cdots \mathrm{N}$ or $\mathrm{H} \cdots \mathrm{O}$ distances, within the range of $2.0-2.2 \AA$, Table 2(d), connecting molecules I and II, which are related only by translation parallel to the $a$ and $b$ axes; the dashed lines in Fig. 6 show these strong hydrogen bonds. Pairs of these planes (related by the two-fold symmetry in the cell) are linked by slightly weaker hydrogen bonds, with $\mathrm{H} \cdots \mathrm{N}$ or $\mathrm{H} \cdots \mathrm{O}$ distances of 2.3-2.6 $\AA$. The two amine groups have different involvements in the hydrogen bonding scheme: in molecule I, both the amine protons are (relatively) weakly hydrogen bonded (between monolayers), while in II, H (221a) is involved in a strong hydrogen bond (within the monolayer) while the other, $H(221 b)$ is less strongly hydrogen bonded (between monolayers); the orientations and the mobilities of the amine groups are thus expected to be different. This can account for the differences found in $T_{1}$ values of $\alpha$ carbons.

The arrangement of the molecules having their 'heads' (amine and amide groups) together, all contributing to the hydrogen bonding network, leaves the 'tails' (the alkyl groups) pointing away from the bilayer and directed towards the tails of the next bilayer, $\mathrm{Fig}$. 7. The shortest $\mathrm{C} \cdots \mathrm{C}$ distance between methyl groups of neighbouring layers is 3.861(15) $\AA$, for $\mathrm{C}(15) \cdot \cdots \mathrm{C}\left(241^{\prime}\right)$ and there is no other distance less than $4.2 \AA$, suggesting very loose packing here. This is reflected in the 


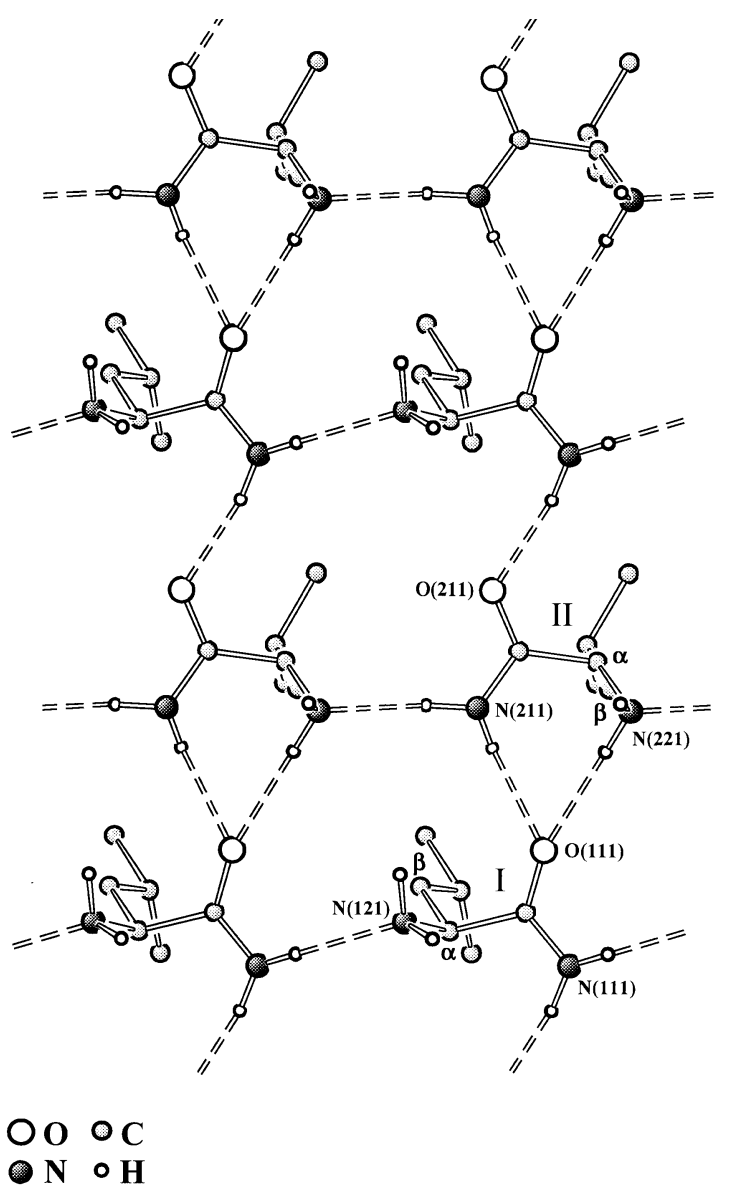

Fig. 6 View of a monolayer in the ab plane of the crystal of $\mathrm{L}$ leucinamide, in which the molecules are connected by strong hydrogen bonds

morphology of the crystals which are normally wafer-thin (painstaking efforts were required to grow crystals to a thickness suitable for the $X$-ray analysis).

\section{Conclusions}

The CP/M A S N M R and FTIR spectra of solid L-leucinamide showed two inequivalent molecules in its unit cell and suggested that intermolecular hydrogen bonding can account for it. X - R ay diffraction studies confirmed this. In addition, the ${ }^{13} \mathrm{C}$ spinlattice relaxation times in the both rotating and laboratory frame measurements suggested that the motions of the two molecules are different. This can be explained by the hydrogen bonds formed in the crystal; in one of the molecules, one amine proton is strongly hydrogen bonded and the other one is less strongly bonded, while in the other molecule, both amine protons are engaged in the weaker hydrogen bonding. This allows the amino group in one molecule to move more easily than in the other. This freedom of motion is likely to be reflected by the adjacent carbon atoms and could account for the differences in $T_{1}$ observed for the $\alpha$ and $\beta$ carbon atoms of the two molecules.

\section{Acknowledgements}

Yulan Wang thanks the BBSRC for provision of a Studentship.

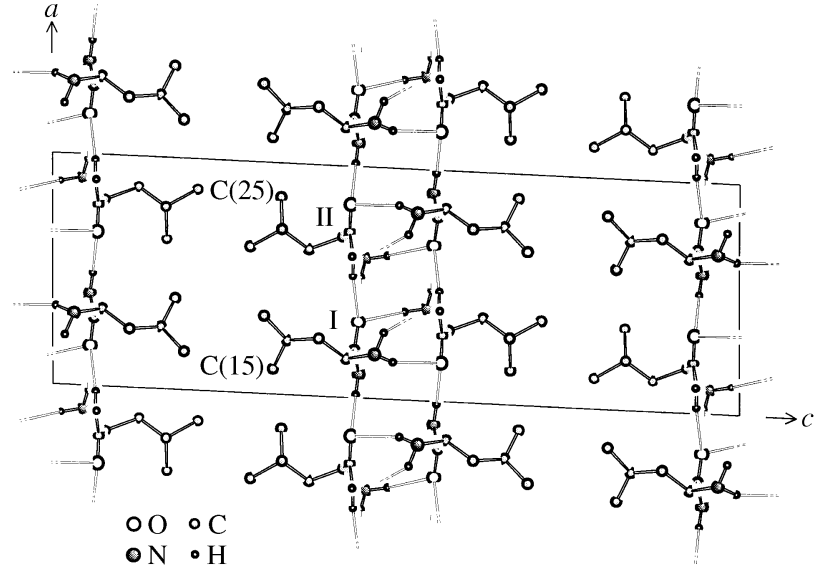

Fig. 7 Packing arrangements in the crystals of L-leucinamide, viewed down the $b$ axis. Hydrogen bonding within the bilayers is shown; the lack of contacts between the bilayers is apparent.

The financial support from the BBSRC from its Competitive Strategic $G$ rant is gratefully acknowledged. We also thank Professor $L$. Sutcliffe for his advice on crystal growing. H elp from DrE.N. Vulfson is gratefully acknowledged.

We are grateful to a referee for helpful comments on the chemical shifts of $\alpha$ and $\beta$ carbon atoms and suggestions as to the origin of line-broadening effects.

\section{R eferences}

1 R. Lopez-Fandino, I. Gill and E. N. Vulfson, Biotechnol. Bioeng., 1994, 43, 1024.

2 R. Lopez-Fandino, I. Gill and E. N. Vulfson, Biotechnol. Bioeng., 1994, 43, 1016

3 I. Gill and E. N. Vulfson, Biotechnol. Bioeng., 1994, 12, 118.

4 P. S. Belton and Y. L. Wang, M ol. Phys., 1997, 90, 119.

5 A . Pines, M. G. Gibby and J. S. Waugh, J. C hem. Phys., 1973, 57, 569.

6 J. Tegenfeldt and U. H acberten, J. M agn. Reson., 1979, 36, 453.

7 W. L. E arl and D. L. VanderH art, J. M agn. Reson., 1982, 48, 35

8 J. S. Frye and G. E. M aciel, J. M agn. Reson., 1982, 48, 125.

9 J. S. H artman and J. A. Ripmeester, Chem. Phys. Lett., 1990, 168, 219.

10 D. A. Torchia, J. M agn. Reson., 1978, 30,613.

$11 \mathrm{~J}$. Schaefer, E. O. Stejskal and R. Buchdahl, M acromolecules, 1977, 10, 384.

12 R. Voclkel, A ngew. Chem., Int. Ed. Engl., 1988, 27, 1468

13 G. M. Sheldrick, A cta Crystallogr., Sect. A, 1990, 46, 467.

14 G. M. Sheldrick, SHELXL-93-Program for crystal structure refinement, Institut für A norg, Chemie, G öttingen, G ermany, 1993.

15 International Tables for X-ray Crystallography, Kynoch Press, Birmingham, 1974, vol. 4, pp. 99 and 149.

16 S. N. A nderson, R. L. Richards and D. L. Hughes, J. Chem. Soc., Dalton Trans., 1986, 245.

17 P. S. Belton, A. M. G il and S. F. Tanner, Solid State N uclear M agn. Reson., 1992, 1, 67 .

18 L. B. A lemany, D. M. G rant, R. J. Pugmire, T. D. Alger and K. W. Zilm, J. Am. Chem. Soc., 1983, 105, 2133.

19 J. Schaefer, E. O. Stejskal, T. R. Steger, M. D. Sefcik and R. A. M cK ay, M acromolecules, 1980, 13, 1121.

20 D. L. Vanderhant, W. L. Earl and A. N. G arroway, J. M agn. R eson., 1981, 44, 361.
Paper 6/07971G

Received 25th N ovember 1996 A ccepted 6th February 1997 